\title{
CONFLITOS E CONSENSOS NA EXIGIBILIDADE JUDICIAL DO DIREITO À EDUCAÇÃO BÁSICA
}

\author{
Adriana Dragone SiLVEIRA*
}

\begin{abstract}
RESUMO: O presente artigo analisa os obstáculos enfrentados para a exigibilidade do direito à educação, por meio do recurso ao Judiciário, relacionados aos argumentos sobre a escassez de recursos para a concretização deste direito, a impossibilidade de interferência do Judiciário no poder discricionário do Executivo e a satisfação das demandas difusas e coletivas referentes à formulação e a concretização de políticas públicas. Os temas são discutidos a partir dos limites apresentados para a efetivação deste direito social e das proposições para a sua superação, recorrendo à literatura e às decisões judiciais do Supremo Tribunal Federal e do Tribunal de Justiça de São Paulo.
\end{abstract}

Palavras-chave: Direito à educação. Poder Judiciário. Políticas públicas educacionais.

\section{CONFLICT AND CONSENSUS IN THE LEGAL LIABILITY OF THE RIGHT TO BASIC EDUCATION}

ABSTRACT: This paper analyzes the obstacles faced for the enforceability of the right to the education, by appeal to the Judiciary, related to the deficit of resources for this right concretion; to the impossibility of Judiciary from intervening in the Executive Discretionary Power and to the satisfaction the diffuse and collective demands related to formulation and implementation of public policies. The subjects are discussed from the limits presented for the realization this social right, and proposals for it overcoming, appealing to the literature and the sentences of the Supreme Court and the São Paulo Justice Court.

Key words: Right to education. Judiciary. Public policy education. Education financing.

\footnotetext{
* $\quad$ Doutora em Educação e professora do Departamento de Planejamento e Administração Escolar da
} Universidade Federal do Paraná (UFPR). E-mail: adrianadragone@yahoo.com.br 


\title{
CONFLITS ET CONSENSUS DANS L'EXIGIBILITÉ JUDICIAIRE DU DROIT À L'ÉDUCATION DE BASE
}

\begin{abstract}
RÉSUMÉ: Le présent article analyse les obstacles confrontés pour l'exigibilité du droit à l'éducation, en utilisant l'appel au Judiciaire, concernant les arguments d'un manque de ressources pour la matérialisation de ce droit, de l'impossibilité d'interférence du Judiciaire dans le pouvoir discrétionnaire de l'Exécutif et de la satisfaction des exigences diffuses et collectives liées à la formulation et à la concrétisation de politiques publiques. Les sujets sont discutés à partir des limites présentées pour la réalisation de ce droit social et des propositions pour le dépasser, en faisant appel à la littérature et aux décisions judiciaires de la Cour d'Appel Fédérale et de la Cour d'Appel de São Paulo.
\end{abstract}

Mots-clés: Droit à l'éducation. Pouvoir Judiciaire. Politiques publiques scolaires.

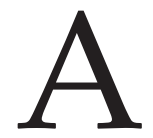

Constituição Federal de 1988 (CF/88) define a República Federativa do Brasil como "Estado Democrático de Direito", estabelecendo no parágrafo único do artigo $1^{\mathrm{o}}$ que "todo poder emana do povo, que o exerce por meio de representantes eleitos diretamente" (BRASIL, 1988, art. 1ํ). A noção de Estado de direito, conceito de inspiração liberal, segundo Silva (2001), tem como características básicas a submissão do poder estatal à lei, a separação de poderes e a enunciação e garantia dos direitos individuais. O Estado democrático funda-se no princípio da soberania popular, não se exaurindo na formação das instituições representativas, mas visa à realização do princípio democrático como garantia dos direitos fundamentais. ${ }^{1}$

A caracterização do Estado democrático de direito não significa a união formal dos conceitos de Estado democrático e Estado de direito, mas de submissão da ordem jurídica em relação aos valores democráticos e aos interesses coletivos para a transformação do status quo. A expressão utilizada pela $\mathrm{CF} / 88$ é a expressão mais adequada, “em que o 'democrático' qualifica o Estado, o que irradia os valores da democracia sobre todos os elementos constitutivos do Estado e, pois, também sobre a ordem jurídica" (SILVA, 2001, p. 123).

Os direitos e garantias individuais definidos na $\mathrm{CF} / 88$ receberam máxima proteção, não sendo permitidas emendas ao texto constitucional que possam limitá-los ou aboli-los (BRASIL, 1988, art. 60, §4 , IV). Com relação aos direitos sociais, a Constituição enuncia-os em capítulo próprio, abrangendo a educação, a saúde, a alimentação, o trabalho, a moradia, o lazer, a segurança, a previdência social, a proteção à maternidade e à infância, a assistência aos desamparados (art. $6^{\circ}$ ).

De acordo com Bonavides (2009a, p. 374), os direitos sociais formam a "espinha dorsal do Estado social brasileiro". Contudo, o que isto representa para a sua exigibilidade? Há diferença quanto à natureza entre os direitos para o reconhecimento 
e execução pelo Estado? Autores como Holmes e Sunstein (1999) e Abramovich e Courtis (2002) defendem que todos os direitos, mesmo os civis e políticos, necessitam de obrigações negativas e positivas por parte do Estado, com a destinação de recursos e criação de condições, sendo a distinção entre os direitos apenas uma questão de grau e não de aspectos substanciais. Todavia, nos direitos econômicos, sociais e culturais a faceta mais visível refere-se às obrigações de fazer por parte do Estado.

Nas últimas décadas os direitos sociais têm sido contestados por grupos sociais, exigindo o cumprimento da legislação por meio do Judiciário. Abramovich e Courtis (2002), no que tange a possibilidade de reclamar perante o tribunal em caso de descumprimento da obrigação devida dos direitos econômicos, sociais e culturais, sublinham alguns obstáculos como: (i) a falta de especificação concreta do conteúdo dos direitos; (ii) autorrestrição do Poder Judiciário frente a questões políticas e técnicas; (iii) ausência de mecanismos processuais adequados para a sua tutela; (iv) escassa tradição de controle judicial envolvendo a matéria.

$\mathrm{Na} \mathrm{CF} / 88$ o direito à educação é reconhecido como um direito de natureza social, portanto sua proteção vai além da tutela individual. Nesse sentido, o Judiciário, quando demandado a analisar ações envolvendo esta temática, reconhece que o Executivo e Legislativo estão agindo em omissão, determinando obrigações do Estado para a garantia deste direito?

Em análise de decisões envolvendo o direito à educação básica, denotou-se que os argumentos contra o acatamento dessas demandas estão relacionados, principalmente, às seguintes questões: falta de recursos; impossibilidade de interferência do Judiciário no poder discricionário do Executivo; ações envolvendo a formulação e a implementação de políticas públicas por meio de pedidos que abrangiam com interesses difusos e coletivos. ${ }^{2}$

Dessa forma, esse artigo objetiva discutir algumas proposições para enfrentar esses principais obstáculos apresentados para a garantia do direito à educação por meio do Poder Judiciário, recorrendo à literatura sobre o tema e às decisões do Tribunal de Justiça de São Paulo (TJ-SP) e do Supremo Tribunal Federal (STF), procurando depreender as possibilidades de ampliação da exigibilidade do direito à educação por meio dos argumentos jurídicos favoráveis à superação dos limites neste processo.

\section{Capacidade econômica do Estado para a concretização dos direitos educacionais}

Os municípios, em diversas ações julgadas pelo TJ-SP nos últimos anos que reivindicavam matrículas em educação infantil (EI), atendimento especializado às 
crianças e adolescentes com necessidades educacionais especiais, assim como programas de transporte escolar, argumentaram que sua atuação deveria ser realizada na medida das suas possibilidades estruturais e financeiras, ou seja, na reserva do possível.

De acordo com Krell (2002, p. 52), a construção teórica da reserva do possível tem sua origem na Alemanha e representa uma adaptação, cujo entendimento pressupõe que a:

[...] construção de direitos subjetivos à prestação material de serviços públicos pelo Estado está sujeita à condição da disponibilidade dos respectivos recursos. Ao mesmo tempo, a decisão sobre a disponibilidade dos mesmos estaria localizada no campo discricionário das decisões governamentais e dos parlamentos, através da composição dos orçamentos públicos.

Segundo Sarlet e Figueiredo (2008, p. 27), uma das principais objeções para a concretização dos direitos sociais refere-se à dimensão econômica desses direitos, pois se sustenta na alegação de que as prestações necessárias para a sua efetivação dependem da "disponibilidade financeira e da capacidade jurídica de quem tenha o dever de assegurá-las".

Os estados e municípios, com competências expressamente declaradas na legislação, poderiam utilizar da ponderação referente ao limite orçamentário, por meio da reserva do possível, para o não atendimento dos pedidos relacionados à educação, principalmente, fora do conceito abarcado pelo direito público subjetivo - por exemplo, a EI e o ensino médio -, considerando apenas o ensino fundamental como obrigatório na versão original da $\mathrm{CF} / 88$ ? E para o não atendimento às creches, após a ampliação da obrigatoriedade com a Emenda Constitucional n. 59 de 2009?

Para alguns autores, estabelece-se uma controvérsia sobre a possibilidade de exigir ao Estado, por meio de políticas públicas, a implementação dos direitos subjetivos $^{3}$ no Judiciário, quando estes direitos estão relacionados à existência de limites do orçamento público. Assim, sustenta-se que a prestação desses direitos estaria condicionada à reserva do possível, e pela relação desta com as competências constitucionais e com o princípio da separação dos Poderes.

Segundo Krell (op. cit., p. 52), a Corte alemã embasou-se no argumento da reserva do possível quando "recusou a tese de que o Estado seria obrigado a criar a quantidade suficiente de vagas nas universidades públicas para atender a todos os candidatos", entendendo que existem limitações para o atendimento de todas as demandas.

Para Krell (2002), a reserva do possível é fruto de um direito constitucional comparado equivocado, sendo questionável a transferência de teorias jurídicas, 
desenvolvidas em países "centrais", com base em realidades completamente diferentes, para países como o Brasil, que não implantaram um Estado de bem-estar social.

A Alemanha optou pela não inclusão de direitos sociais na Lei Fundamental de 1949, com exceção do direito da mãe à proteção e assistência por parte da comunidade, representando o conceito do "Estado social" uma "norma-fim de Estado", que "fixa, de maneira obrigatória, as tarefas e a direção da atuação estatal presente e futura, sem, no entanto, criar direitos subjetivos para a sua realização". A doutrina alemã se refere a essas normas constitucionais como "mandados" e não propriamente "direitos" (KRELL, op. cit., p. 48).

A CF/88 brasileira, ao contrário da alemã, inseriu uma vasta gama de direitos sociais, sendo estes reconhecidos também como fundamentais. E a "tentativa de relativizá-los e de retirar-lhes a qualidade da 'fundamentalidade' não traz nenhuma vantagem, mas é, ao contrário, perigosa [...]" (idem, ibid., p. 49). Nesse sentido, para este autor, condicionar a realização dos direitos econômicos, sociais e culturais à existência de recursos do Estado significa relativizar a sua universalidade, podendo estes serem considerados direitos de segunda categoria.

Para Sarlet e Figueiredo (2008, p. 37) as objeções atreladas à reserva do possível não podem prevalecer nas hipóteses em que já se reconheceu como "direito subjetivo definitivo a prestações" e para afastar a responsabilidade do Estado com relação ao mínimo existencial.

Para Lopes (2008, p. 181), "a reserva do possível", de caráter econômico, se confunde com a impossibilidade técnica ou com a escassez de recursos:

Impossibilidade técnica existe, por exemplo, quando se requer a distribuição geral e gratuita de um medicamento ainda em fase experimental. O remédio existe, mas não é produzido em escala industrial (está em fase experimental). Não é produzido porque não se sabem ainda os resultados de sua aplicação a todas as populações. Há escassez quando o nível de produção industrial, embora existente, não é suficiente para garantir a todos. Assim, há escassez quando se verifica que um determinado medicamento (ou tratamento) existe, mas seu custo é tal que sua provisão impedirá o fornecimento de outros medicamentos (ou tratamento) ou mesmo que exigirá o corte de outras despesas em outras áreas. Impossibilidade econômica, não técnica, existe quando se requer a distribuição de um medicamento já testado e comercializado, cujo custo faz dele um remédio para poucos. Note-se que, em casos assim, está em jogo o caráter igualitário do acesso à saúde. (Grifo nosso)

Dessa maneira, o que deveria ser pedido e concedido precisaria estar relacionado ao caráter universal e igualitário, contemplando a todos os que se encontram naquela situação e não podendo conceder a uns e não a outros (LOPES, 2008).

Muitas ações sobre educação julgadas pelos Tribunais de Justiça nos últimos anos requisitam matrículas em creches. Observando-se os dados de atendimento da população de 0 a 3 anos (18,4\%), torna-se perceptível que o grupo mais alijado é a 
população preta/parda (16,7\%) e mais pobre (12,2\%) (BRASIL, 2009). Nessa situação, quando se reivindica a matrícula e os municípios a negam, tendo em vista a limitação de recursos, está em jogo o caráter universal e igualitário deste atendimento, pois para algumas crianças a matrícula é concedida e a outras faltam vagas.

Considerando as dificuldades orçamentárias para a implementação dos direitos sociais, Lopes (2008) explana que a decisão judicial deveria permitir a adequação do Estado, fixando prazos e metas a ser atingidos, o que já ocorre no âmbito dos inquéritos civis promovidos pelo Ministério Público (MP), com Termo de Ajustamento de Conduta (TAC). Nesse sentido, há uma decisão da 7ª Câmara de Direito Público do TJ-SP, relatada pelo desembargador Nogueira Diefenthaler, reconhecendo que a regra constitucional veda o início de programas ou projetos não incluídos em lei orçamentária, "de forma que o provimento jurisdicional não pode determinar, sem a adoção desta providência preliminar, a instalação de creches e pré-escolas". A decisão estipulou que o município fosse condenado a incluir as verbas necessárias à instalação das creches no projeto de lei orçamentária (SÃO PAULO, 2008).

Outro fator relevante a se considerar na análise da reserva do possível e do litígio de direitos sociais está relacionado ao pedido de caráter coletivo, em detrimento de pedido individual ou individual homogêneo. Para Lopes (2008), as demandas na esfera orçamentária para a implementação de direitos têm a vantagem de minimizar os tratamentos desiguais. A requisição da implementação de direitos pela esfera orçamentária constitui-se, também, numa maneira de ampliar o acesso à justiça, considerando que nem todos os cidadãos a procuram para requerer os seus direitos (SANTOS, 2007).

A posição de Lopes (op. cit.) ainda está distante das decisões dos Tribunais. Análise das decisões do TJ-SP indica que as ações com pedidos individuais são atendidas com mais facilidade, mas quando requisitam medidas para ampliação do atendimento ou para criação de políticas, o Tribunal não se mostra coeso para a concessão, tendo em vista o argumento da impossibilidade de interferência do Judiciário na condução de políticas públicas e na questão orçamentária (SILVEIRA, 2011).

Duarte (2007) observa que, aceitando-se que o objetivo dos direitos sociais "é corrigir desigualdades próprias das sociedades de classes, aproximando grupos ou categorias marginalizadas", a sua implementação, não obstante o reconhecimento expresso da universalidade, demanda "a escolha de alvos prioritários, ou seja, grupos de pessoas que se encontram em uma mesma posição de carência ou vulnerabilidade" (p. 700). Para reiterar sua afirmação, a autora destaca a noção de progressividade dos direitos sociais e a cláusula de proibição do retrocesso social.

Duarte (op. cit.) discute a noção de progressividade para a plena realização dos direitos econômicos, sociais e culturais, de acordo com o Comentário Geral n.3, 
de 1990, do Comitê de Direitos Econômicos, Sociais e Culturais da Organização das Nações Unidas (ONU).

De acordo com as Nações Unidas, o conceito de progressividade indica que a plena realização dos direitos econômicos, sociais e culturais, de modo geral, não poderá ser atingida em um curto período de tempo. Entretanto, para o Comitê, a progressividade não deve ser interpretada como uma forma de esvaziar a obrigação de conteúdo substantivo. Ela seria apenas uma forma de levar em conta a realidade do mundo concreto e as dificuldades envolvidas no que concerne à tarefa de assegurar a plena realização dos direitos econômicos, sociais e culturais. (Idem, ibid., p. 699)

A progressividade impõe deveres ao Estado, adotando medidas "até o máximo de seus recursos disponíveis" (art. $2^{\text {o }}$ do Pidesc), visando assegurar progressivamente o pleno exercício dos direitos garantidos pelo Pacto, sempre como observa Duarte (op. cit., p. 701), em "evolução ascendente contínua". Dessa forma, a progressividade cria um "empecilho ao retrocesso da política social do Estado que, tendo alcançado um certo nível de proteção dos respectivos direitos, não pode retroceder e baixar o padrão de vida da comunidade, já que a cláusula de proibição do retrocesso social protege o núcleo essencial dos direitos sociais" (p. 700).

Para a avaliação do cumprimento das obrigações estatais, Duarte (2007, p. 701) salienta, também, o conceito de núcleo mínimo obrigatório (minimum core obligation): "Assim, diante de recursos escassos, o Estado deverá demonstrar que empenhou todos os esforços para utilizar os recursos disponíveis, tendo em vista, no mínimo, a satisfação daquilo que foi eleito como prioritário, ou seja, suas obrigações mínimas essenciais".

Com relação ao direito à educação, o que se estabeleceria como o mínimo existencial ou núcleo mínimo obrigatório? Somente o ensino obrigatório, considerado como direito público subjetivo, ou o conceito de educação básica, definido pela LDB/96, da creche ao ensino médio?

Acredita-se que o argumento da progressividade e da proibição do retrocesso social contribui apenas para a não redução do atendimento. Porém, considerando as ações envolvendo pedidos referentes à matrícula em creche e refletindo o contexto de crescimento da demanda pelo atendimento da primeira etapa da educação básica, esses conceitos não favorecem a superação do obstáculo concernente ao limite orçamentário para atendimento dessas demandas. Da mesma maneira, coloca-se o conceito do núcleo mínimo obrigatório, pois se for aceito que este se vincula ao que estaria abarcado pelo conceito de "obrigatório" na Constituição (art. 208, inciso I), a creche não estaria contemplada.

Outra declaração legal, que pode oferecer dificuldades à ampliação dos demais níveis e modalidades da educação, refere-se ao artigo 212 da CF/88, §2º , o qual 
define que a distribuição dos recursos assegurará prioridade ao atendimento das necessidades do ensino obrigatório.

Desse modo, poderiam os municípios utilizar-se da restrição orçamentária para atender aos pedidos judiciais, alegando limites para a ampliação do atendimento ou para a garantia de um conceito mais amplo de direito à educação?

Algumas decisões do TJ-SP e do STF não concordam com a possibilidade de alegação da falta de previsão orçamentária para atendimento da EI. Compila-se excerto da decisão da Câmara Especial do TJ-SP, relatada pelo desembargador Borelli Machado: "a satisfação do comando imposto pela tutela jurisdicional deve ser viabilizada com base nas receitas específicas já previstas no orçamento ou, se o caso, com base em créditos adicionais obtidos com a necessária autorização legislativa" (SÃO PAULO, 2002).

O ministro Celso de Mello, do STF, relator de recurso impetrado pelo MP contra a decisão do TJ-SP, que reivindicava o acesso à EI, argumentou sobre a cláusula da reserva do possível, para efetivação dos direitos de segunda geração:

Não se ignora que a realização dos direitos econômicos, sociais e culturais - além de caracterizar-se pela gradualidade de seu processo de concretização - depende, em grande medida, de um inescapável vínculo financeiro subordinado às possibilidades orçamentárias do Estado, de tal modo que, comprovada, objetivamente, a alegação de incapacidade econômico-financeira da pessoa estatal, desta não se poderá razoavelmente exigir, então, considerada a limitação material referida, a imediata efetivação do comando fundado no texto da Carta Política.

Não se mostrará lícito, contudo, ao Poder Público, em tal hipótese, criar obstáculo artificial que revele - a partir de indevida manipulação de sua atividade financeira e/ou política - administrativa - o ilegítimo, arbitrário e censurável propósito de fraudar, de frustrar e de inviabilizar o estabelecimento e a preservação, em favor da pessoa e dos cidadãos, de condições materiais mínimas de existência.

[...] a cláusula da "reserva do possível" - ressalvada a ocorrência de justo motivo objetivamente aferível - não pode ser invocada, pelo Estado, com a finalidade de exonerar-se dolosamente do cumprimento de suas obrigações constitucionais, notadamente quando, dessa conduta governamental negativa, puder resultar nulificação ou, até mesmo, aniquilação de direitos constitucionais [...]. (BRASIL, 2005)

Cabe pontuar que essa decisão apresenta uma ressalva para que a reserva do possível seja invocada: "justo motivo objetivamente aferível". A escassez de recursos, comprovada pelo orçamento, poderia estar nesta classificação?

A Câmara Especial do TJ-SP, em decisão relatada pelo desembargador do TJ-SP, Álvaro Lazzarini, destaca que o argumento da limitação orçamentária para a não abertura de novas creches dependeria da "comprovação de o Administrador Municipal ter esgotado as verbas orçamentárias específicas destinadas a esse direito fundamental" (SÃO PAULO, 2001a). 
Segundo Lopes (2008, p. 179 e 191), “há sim limites orçamentários que se podem alegar, mas como orçamentos não são coisas da natureza, mas frutos de decisões políticas", a reserva do possível "não pode ser acatada quando Executivo e Legislativo manipulam de tal forma o orçamento a criá-la de forma artificial ou, melhor, de criá-la, quando observadas as outras condições, ela não existiria".

Na posição de Caliendo (2008, p. 202, grifos do autor), "se fizermos uma leve comparação entre o que o governo orça para gastar em saúde, educação e segurança e o que gasta pagando a dívida pública, veremos que existe uma reserva do possível geral no Brasil que impede os gastos sociais que se chama dívida pública".

O principal problema, como expõe Galdino (2007, p. 284), e neste aspecto concorda-se com o autor, reside na "opção política de não se gastar dinheiro com aquele mesmo 'direito"'. "O argumento da 'exaustão orçamentária' presta-se unicamente a encobrir as trágicas escolhas que deixaram de fora do universo do possível a tutela de um determinado 'direito"'.

Sobre a ineficácia do argumento da insuficiência de recursos, enfatiza-se a decisão do STF, relatada pelo ministro Marco Aurélio:

Conforme preceitua o artigo 208, inciso IV, da Carta Federal, consubstancia dever do Estado a educação, garantindo o atendimento em creche e pré-escola às crianças de zero a seis anos de idade. O Estado - União, Estados propriamente ditos, ou seja, unidades federadas, e Municípios - deve aparelhar-se para a observância irrestrita dos ditames constitucionais, não cabendo tergiversar mediante escusas relacionadas com a deficiência de caixa. (BRASIL, 2004)

Cabe destacar, ainda, que a utilização do argumento da reserva do possível por alguns membros do Judiciário livra-os de serem acusados de violar o princípio da separação de poderes (ZANITELLI, 2008). Todavia, é preciso mudar a concepção de que a efetivação dos direitos deve estar condicionada aos recursos financeiros; o argumento deve ser o contrário, os recursos devem ser direcionados à concretização dos direitos já definidos pela nossa legislação.

\section{Interferência do Judiciário no poder discricionário do Executivo: princípio da separação de poderes}

Para parte da doutrina jurídica, o controle dos atos administrativos pelo Judiciário esbarra na análise da discricionariedade da administração, considerando o princípio da separação de poderes. A definição da política pública concentra-se no Executivo e no Legislativo. Todavia, segundo Krell (2002, p. 101), onde “o processo político (Legislativo, Executivo) falha ou se omite na implementação de políticas públicas e dos objetivos sociais nelas implicados, cabe ao Poder Judiciário tomar uma 
atitude ativa na realização desses fins sociais através da correição da prestação dos serviços básicos". Esse fato implicaria invasão do Judiciário em áreas do Executivo, ou os juízes estariam cumprindo uma tarefa desenhada pela própria constituição?

Segundo Bonavides (2009b), o princípio da separação dos poderes, no Estado social, tem outro caráter e dimensões. Ele não pode ser utilizado para negar as características deste Estado, servindo para paralisar as reivindicações relacionadas aos direitos sociais.

O princípio da separação dos poderes, segundo Bonavides (2009b), representou seu papel histórico, ajudando a implantar a consciência dos direitos e garantias individuais e um mecanismo eficaz no combate aos déspotas do absolutismo. Na lógica do Estado social, é preciso diálogo entre os poderes para a efetivação dos direitos fundamentais, tornando-se desejável a releitura da teoria da separação dos poderes.

Sendo assim, a intervenção do Judiciário, quando comprovado o não cumprimento de um dever, não significa transferência de competências, mas exigência de uma tarefa constitucional (SANTOS, 2007).

Segundo Barroso (2009, p. 340), quando os juízes são capazes de fundamentar racionalmente suas decisões, com base na Constituição, atuam de maneira legítima. A jurisdição constitucional, "quando bem exercida, é antes uma garantia para a democracia do que um risco". Todavia, importa ressaltar que "já não subsiste no mundo contemporâneo a crença na ideia liberal - positivista de objetividade plena do ordenamento e de neutralidade absoluta do intérprete" (p. 340-341). Mesmo o Judiciário tem seus limites:

\footnotetext{
Note-se que os três Poderes interpretam a Constituição, e sua atuação deve respeitar os valores e promover os fins nela previstos. No arranjo institucional em vigor, em caso de divergência na interpretação das normas constitucionais ou legais, a palavra final é do Judiciário. Essa primazia não significa, porém, que toda e qualquer matéria deva ser decidida em um tribunal. Nem muito menos legitima a arrogância judicial. (BARROSO, op. cit., p. 343)
}

A decisão, para não estar relacionada ao ativismo do juiz, deve observar as normas jurídicas. E com relação ao direito à educação há um rol de definições tanto na CF/88, como no Estatuto da Criança e do Adolescente de 1990 (ECA) e na Lei de Diretrizes e Bases da Educação Nacional de 1996, que estabelecem deveres do Estado, divisão de responsabilidades entre os entes federativos e destinação de recursos para a concretização deste direito.

Em diversas decisões do TJ-SP discutiu-se o limite do poder discricionário do Executivo no que se refere à educação. Segundo Frischeisen (2000, p. 94-95), o administrador público está vinculado à Constituição e às leis infraconstitucionais, 
pois a $\mathrm{CF} / 88$ estabelece claramente políticas públicas a serem cumpridas, tendo como finalidade o bem-estar e a justiça social, sendo "que os atos emanados da administração no cumprimento podem ser mencionados como vinculados e não discricionários". Os atos vinculados "são aqueles em que não existe margem de subjetividade para a Administração decidir sobre a melhor forma de solucionar determinado caso concreto".

Portanto, parece pertinente dizer que a discussão sobre a discricionariedade do administrador público não se dá quanto ao dever, mas "quanto aos meios que está usando para a implementação de políticas públicas, se o escolhido era o melhor, o mais adequado, o mais razoável para possibilitar o eficaz exercício dos direitos sociais" (FRISCHEISEN, 2000, p. 114; grifo meu). Para esta autora, as dúvidas sobre essa margem de discricionariedade deveriam ser dirimidas pelo Judiciário, e os juízes, ao decidirem sobre isto, não estariam substituindo o Executivo, mas realizando o cumprimento da Constituição.

Em algumas ações julgadas pelo TJ-SP e STF, que abordaram o poder discricionário do Executivo para com a educação, emergem diferentes opiniões entre os membros do Judiciário. Os magistrados favoráveis à interferência do Judiciário afirmam que, com relação à educação, o poder público não tem discricionariedade, considerando as obrigações impostas pela legislação. O exercício da discricionariedade seria cumprido na maneira de satisfazer as obrigações.

OSTF, em ação envolvendo EI, relatada pelo ministro Celso de Melo, salientou que a mesma, por qualificar-se como direito fundamental, não se expõe a avaliações discricionárias (BRASIL, 2005). Esta decisão colaborou para as decisões favoráveis do TJ-SP, como as da Câmara Especial, relatada pela desembargadora Maria Olivia Alves. Segundo essa decisão, a discricionariedade do administrador público quanto à EI se realizaria apenas sobre a forma de satisfazer essa obrigação (SÃO PAULO, 2006). No mesmo sentido, para a decisão relatada pelo desembargador Sidnei Beneti, defender a não interferência do Judiciário, após reconhecer o direito das crianças, seria negar a própria atividade do Judiciário (SÃO PAULO, 2007).

Todavia, algumas decisões do TJ-SP, ainda que em menor número, são favoráveis aos argumentos das Fazendas Públicas, salientando que a decisão sobre a conveniência e a oportunidade de realizar atos físicos como obras e contratações cabem, com exclusividade, ao Poder Executivo, não sendo possível o Judiciário intervir. Este obstáculo foi aceito principalmente nas ações que reivindicavam vagas em EI por meio de pedidos difusos e coletivos, matrícula próxima da residência, transporte escolar, construção de salas de aulas, reorganização das escolas no estado de São Paulo. Notadamente, os recursos judiciais envolvendo demandas concentradas em interesses difusos e coletivos evidenciaram a maior divergência entre os 
desembargadores, no que se refere à interferência do Judiciário no planejamento do Executivo, ou seja, à elaboração e à concretização de políticas públicas.

\section{Exigibilidade dos direitos educacionais por meio de demandas indi- viduais e coletivas}

Os direitos sociais extrapolam os mecanismos individuais (LOPES, 2008). Todavia, nas ações julgadas pelo TJ-SP (1991-2008) que demandavam a requisição de direitos individuais, os desembargadores foram mais favoráveis em reconhecer este direito como líquido e certo e sua exigibilidade perante o Judiciário (SILVEIRA, 2011). Os pedidos que abrangiam interesses transindividuais (difusos e coletivos) tiveram suas justificativas para a não concessão, baseadas no argumento da titularidade do pedido, sendo o mesmo genérico, sem a determinação do objeto.

De acordo com Frischeisen (2000), o processo de judicialização das demandas coletivas é consequência da positivação dos direitos sociais na Constituição. E no que se refere aos instrumentos jurídicos para a exigibilidade de demandas coletivas, destacam-se a ação civil pública e a legitimação do MP para atuar como defensor dos interesses coletivos, principalmente no que se refere aos direitos concernentes à infância e juventude, as atribuições conferidas ao MP pelo ECA, com destaque para o artigo 208 deste Estatuto.

Sobre a concessão dos pedidos difusos e coletivos para vaga em instituição de EI, a decisão do TJ-SP, na Apelação Cível n. 81.514-0/9-00, da Câmara Especial, relatada pelo desembargador do TJ-SP, Luiz Tâmbara, postulou: "Cumpre ao Poder Judiciário, por função típica, dizer o direito, assinando, se o caso, norma de conduta individual, concreta, daí porque o pedido há de ser certo, em sua extensão, e determinado quanto ao seu objeto" (SÃO PAULO, 2001b, p. 3; grifo nosso). Já o desembargador Gentil Leite, nessa ação, em voto divergente, apontou que seria inconsistente o argumento de determinação do seu objeto, aceitando que a não determinação do pedido em ação civil pública faz parte da natureza deste instrumento, que visa proteger interesses difusos de um grupo indeterminado de pessoas. Justificando sua declaração com o disposto no ECA, artigo 208, parágrafo único: "As hipóteses previstas neste artigo não excluem da proteção judicial outros interesses difusos ou coletivos, próprios da infância e da adolescência, protegidos pela Constituição e pela Lei", e no Código de Processo Civil, artigo 286, inciso II, "permite a indicação de pedido genérico, quando não foi possível determinar, de modo definitivo, as consequências do ato ou do fato ilícito" (SÃO PAULO, 2001b, p. 8).

Se a concretização da educação se dá por meio de políticas públicas, Bucci (2006, p. 31) sublinha que a ação coletiva é o mecanismo mais adequado de acionar 
o controle judicial para a "solução de conflitos envolvendo os direitos sistematizados em políticas públicas". Nesse sentido, questiona se a exigibilidade da educação, como direito social e efetivada por meio de instrumentos individuais, seria um processo socialmente justo, sabendo-se que o atendimento de demandas individuais pode privilegiar somente aqueles que tiveram a oportunidade de acesso ao Judiciário e tiveram seu pedido atendido, em detrimento de outros que também aguardam a prestação do mesmo direito pelo Poder Público e não recorreram a esta forma de exigibilidade.

Nesse sentido, Lopes (2002, p. 131) destaca a dificuldade da defesa de direitos sociais por meio de instrumentos individuais:

[...] a prestação do serviço depende da real existência dos meios: não existindo escolas, hospitais e servidores capazes e em número suficiente para prestar o serviço, o que fazer? Prestá-lo a quem tiver tido a oportunidade e a sorte de obter uma decisão judicial e abandonar a imensa maioria à fila de espera? Seria isto viável de fato e de direito, se o serviço público deve pautar-se pela sua universalidade, impessoalidade e pelo atendimento a quem dele mais precisar e cronologicamente anteceder os outros?

De acordo com Lopes (2006), o Judiciário, ao decidir os casos em bases individuais, corre o risco de julgar com critérios de justiça comutativa (questões individuais) problemas de justiça distributiva (questões coletivas). Da mesma maneira, Barcellos (2008) defende que as ações coletivas são o caminho mais justo para implementação de um direito social, pois favorecem a isonomia e são passíveis de concessão a todos que se encontram naquela situação. Além de evitar sobrecarga ao Judiciário, reduzindo o número de processos semelhantes em ações individuais.

Porém, se concessão de direitos por meio de ações coletivas ainda não consolidou possível posição favorável no Judiciário (SILVEIRA, 2011), as demandas individuais podem ser uma estratégia, talvez não a mais adequada, mas a possível, de fazer com que o poder público implemente ou reformule uma política pública. Quando se trata da educação como direito social, não se pode esquecer que se refere, também, a um direito fundamental de cada pessoa. Justamente, por esta razão não se poderia negar a tutela individual deste direito. Por exemplo, nas ações individuais que reivindicaram a vaga em instituições de EI, os processos individuais procuram dar proteção ao princípio da isonomia entre os cidadãos, pois alguns têm o direito e outros não.

Cabe, ainda, explicitar que a pulverização dos conflitos envolvendo ações coletivas na arena judicial pode ensejar efeitos indesejados, como expõe Bucci (2006), pois a perspectiva, mesmo nessas ações, é a titularidade do indivíduo ou grupo de indivíduos, não se configurando a abrangência do processo de seleção de prioridades e reserva de meios na elaboração do orçamento público. Assim, para uma 
ampliação dos direitos sociais - e, em seu esteio, da educação -, a defesa coletiva deveria caminhar alinhada com a possibilidade de planejamento do orçamento público, e não alijada deste.

Sobre as dificuldades do questionamento judicial de demandas coletivas, ressalte-se, igualmente, que o Judiciário, pela sua estrutura, e, neste contexto, o juiz pela sua formação, estão preparados para analisar conflitos individuais (LOPES, 2006). Nesse caso, a aceitação das demandas coletivas surge como um obstáculo a ser enfrentado, considerando que o principal argumento para a negativa dessas demandas reside na posição dos julgadores de não interferência do Judiciário nas atividades do Executivo.

\section{Considerações finais}

Os obstáculos, discutidos neste artigo, relacionados à exigibilidade judicial do direito à educação vinculam-se, sobretudo, às prioridades que os direitos sociais e, neste contexto, a educação têm na destinação dos recursos por parte de nossos governantes. É importante destacar que a aceitação do argumento da reserva do possível, das limitações orçamentárias para o atendimento de toda a demanda, configura a maneira que os membros do Judiciário encontraram para se livrarem de ser acusados de violar o princípio da separação de poderes, como enfatizado por Zanitelli (2008).

Não é possível deixar que a justificativa da não interferência do Judiciário em atividades do poder discricionário do Executivo seja utilizada para manter a omissão com relação aos direitos já proclamados na legislação, pois a negativa para o acesso infringe o próprio princípio do "Estado democrático de direito" na garantia dos direitos fundamentais a todos, não permitindo que os direitos sejam privilégios de alguns. Portanto, como afirma Santos (2007, p. 34), o Judiciário precisa assumir sua "quota-parte" na responsabilidade para a resolução dos problemas relacionados às injustiças, ou será cada vez mais irrelevante, tanto social como politicamente.

No que se refere à natureza dos pedidos, a tutela dos direitos educacionais deve envolver interesses que transcendem a esfera individual, influenciando o planejamento do orçamento público e o estabelecimento de prazos para o cumprimento das metas a serem atingidas.

Considerando o que foi apresentado, ressalta-se a necessidade de discussão acerca da relação entre o orçamento público e a garantia do direito à educação, ainda mais em um contexto de extensão da educação básica obrigatória, para que o reconhecimento judicial dos direitos proclamados em nossa legislação não se torne inviável quando a sua efetivação estiver relacionada aos limites orçamentários. Nesse 
sentido, é preciso mudar a maneira de pensar o orçamento público, ele deve contemplar os direitos já consagrados na legislação e não a efetivação estar condicionada à existência dos recursos financeiros.

\section{Notas}

1. Os direitos humanos são aqueles no plano internacional assegurados a qualquer pessoa, independentemente de seu vínculo com determinado Estado. Já os direitos fundamentais são os direitos humanos consagrados no plano do direito constitucional de cada Estado, configurando-se como direitos reconhecidos e assegurados por uma determinada Constituição (SARLET; FIGUEREDO, 2008).

2. No ordenamento jurídico brasileiro, o Código Brasileiro de Defesa do Consumidor (art. 81) explicita os conceitos de interesses ou direitos difusos e coletivos ao definir que a defesa dos consumidores e das vítimas poderá também ser exercida de maneira coletiva. Entendem-se como interesses ou direitos difusos os transindividuais, de natureza indivisível, de que sejam titulares pessoas indeterminadas e ligadas por circunstâncias de fato. Os interesses ou direitos coletivos são aqueles de natureza indivisível de que seja titular grupo, categoria ou classe de pessoas ligadas entre si ou com a parte contrária por uma relação jurídica. O Código também define os interesses ou direitos individuais homogêneos como os decorrentes de origem comum, cujos titulares são pessoas determinadas.

3. Um direito subjetivo trata-se de "uma capacidade reconhecida ao indivíduo em decorrência de sua posição especial como membro da comunidade, que se materializa no poder de colocar em movimento normas jurídicas no interesse individual" (DUARTE, 2004, p. 113).

\section{Referências}

ABRAMOVICH, V.; COURTIS, C. Los derechos sociales como derechos exigibles. Madrid: Trotta, 2002.

BARCELLOS, A.P. Constitucionalização das políticas públicas em matéria de direitos fundamentais: o controle político-social e o controle jurídico no espaço democrático. In: SARLET, I.W.; TIMM, L.B. (Org.). Direitos fundamentais: orçamento e "reserva do possível". Porto Alegre: Livraria do Advogado, 2008.

BARROSO, L.R. O controle de constitucionalidade no direito brasileiro: exposição sistemática da doutrina e análise crítica da jurisprudência. 4. ed. São Paulo: Saraiva, 2009.

BONAVIDES, P. Curso de Direito Constitucional. 24. ed. São Paulo: Malheiros, 2009a.

BONAVIDES, P. Do Estado liberal ao Estado social. 9. ed. São Paulo: Malheiros, 2009b.

BRASIL. Conselho de Desenvolvimento Econômico e Social. Observatório da Equidade. As desigualdades de escolarização no Brasil. Brasília, DF, 2009. Disponível em: $<$ http://www.cdes.gov.br/observatoriodaequidade/relatorio2.htm>. Acesso em: 11 dez. 2010. 
BRASIL. Constituição (1988). Constituição da República Federativa do Brasil. Brasília, DF: Senado Federal, 1988.

BRASIL. Supremo Tribunal Federal. Recurso Extraordinário n. 431.773-7, São Paulo, Relator Ministro Marco Aurélio. Brasília, DF, 22 out. 2004.

BRASIL. Supremo Tribunal Federal. Recurso Extraordinário n. 410.715-5, São Paulo, Relator Ministro Celso de Mello. Brasília, DF, 22 nov. 2005.

BUCCI, M.P.D. O conceito de política pública em direito. In: BUCCI, M.P.D. (Org.). Políticas públicas: reflexões sobre o conceito jurídico. São Paulo: Saraiva, 2006. p. 46.

CALIENDO, P. Reserva do possível, direitos fundamentais e tributação. In: SARLET, I.W.; TIMM, L. B. (Org.). Direitos fundamentais: orçamento e "reserva do possível". Porto Alegre: Livraria do Advogado, 2008.

DUARTE, C.S. Direito público subjetivo e políticas educacionais. São Paulo em Perspectiva, São Paulo, v. 18, n. 2, p. 113-118, 2004.

DUARTE, C.S. A educação como um direito fundamental de natureza social. Educação \& Sociedade, Campinas, v. 28, n. 100, p. 691-713, out. 2007.

FRISCHEISEN, L.C.F. Políticas públicas: a responsabilidade do administrador e o Ministério Público. São Paulo: Max Limonada, 2000.

GALDINO, F. O custo dos direitos. In: TORRES, R.L. (Org.). Legitimação dos direitos humanos. 2. ed. rev. ampl. Rio de Janeiro: Renovar, 2007.

HOLMES, S.; SUSTEIN, C.R. The cost of rights: why liberty depends on taxes. New York: Norton, 1999.

KRELL, A.J. Direitos sociais e controle judicial no Brasil e na Alemanha: os (des)caminhos de um direito constitucional "comparado". Porto Alegre: Sergio Antonio Fabris, 2002.

LOPES, J.R.L. Direito subjetivo e direitos sociais: o dilema do Judiciário no Estado social de direito. In: FARIA, J.E. (Org.). Direitos humanos, direitos sociais e justiça. São Paulo: Malheiros, 2002. v.1, p. 113-143.

LOPES, J.R.L. Direitos sociais: teoria e prática. São Paulo: Método, 2006.

LOPES, J.R.L. Em torno da "reserva do possível". In: SARLET, I.W.; TIMM, L.B. (Org.). Direitos fundamentais: orçamento e "reserva do possível". Porto Alegre: Livraria do Advogado, 2008.

SANTOS, B.S. Para uma revolução democrática da justiça. São Paulo: Cortez, 2007. 
SÃO PAULO. Tribunal de Justiça de São Paulo. Apelação Cível n. 70.606-0, 2001. Câmara Especial, relator Álvaro Lazzarini. São Paulo, 15 mar. 2001a.

SÃO PAULO. Tribunal de Justiça de São Paulo. Apelação Cível n. 81.514-0/9-00, Câmara Especial, relator Luiz Tâmbara. São Paulo, 13 dez. 2001b.

SÃO PAULO. Tribunal de Justiça de São Paulo. Embargos Infringentes n. 82.4670/2-01, da Câmara Especial, relator Borelli Machado. São Paulo, 19 ago. 2002.

SÃO PAULO. Tribunal de Justiça de São Paulo. Apelação Cível n. 127.659-0/3-00, Câmara Especial, relatora Maria Olivia Alves. São Paulo, 20 fev. 2006.

SÃO PAULO. Tribunal de Justiça de São Paulo. Apelação Cível n. 142. 040-0/9-00, Câmara Especial, relator Sidnei Beneti. São Paulo, 26 mar. 2007.

SÃO PAULO. Tribunal de Justiça de São Paulo. Apelação Cível n. 601.392-5/8-00, da 7aㅡ Câmara de Direito Público, relator Nogueira Diefenthaler. São Paulo, 12 maio 2008.

SARLET, I.W.; FIGUEIREDO, M.F. Reserva do possível, mínimo existencial e direito à saúde: algumas aproximações. In: SARLET, I.W.; TIMM, L.B. (Org.). Direitos fundamentais: orçamento e "reserva do possível". Porto Alegre: Livraria do Advogado, 2008.

SILVA, J.A. Curso de direito constitucional positivo. 19. ed. São Paulo: Malheiros, 2001.

SILVEIRA, A.A.D. Atuação do Tribunal de Justiça de São Paulo com relação ao direito de crianças e adolescentes à educação. In: REUNIÃO ANUAL DA ASSOCIAÇÃO NACIONAL DE PÓS-GRADUAÇÃO E PESQUISA EM EDUCAÇÃO, 34., 2011, Natal. Anais... Natal: ANPEd, 2011. p. 1-16.

ZANITELLI, L.M. Custos ou competências?: uma ressalva à doutrina da reserva do possível. In: SARLET, I.W.; TIMM, L.B. (Org.). Direitos fundamentais: orçamento e "reserva do possível". Porto Alegre: Livraria do Advogado, 2008.

Recebido em 30 de janeiro de 2012.

Aprovado em 19 de dezembro de 2012. 
